$\underline{\text { Supporting Information }}$

\title{
Investigate the Glass Transition Temperature of Hyperbranched Copolymers with Segmented Monomer Sequence
}

\author{
Yi Shi, ${ }^{1}$ Xiaosong Cao, ${ }^{1}$ Shuangiiang Luo, ${ }^{2}$ Xiaofeng Wang, ${ }^{1}$ Robert W. Graff,,${ }^{1}$ Daqiao \\ $\mathrm{Hu},{ }^{1}$ Ruilan Guo, ${ }^{2}$ and Haifeng Gao $*, 1$ \\ ${ }^{1}$ Department of Chemistry and Biochemistry, University of Notre Dame, Notre Dame, \\ Indiana 46556 \\ ${ }^{2}$ Department of Chemical and Biomolecular Engineering, University of Notre Dame, Notre \\ Dame, Indiana 46556 \\ * Corresponding author. Email: hgao@nd.edu
}




\section{Experimental}

Materials. 2,2-Bis(azidomethyl)propane-1,3-diol was synthesized according to previous report. $^{1-2}$ Triethylene glycol monomethyl ether (Sigma-Aldrich, $>97.0 \%$ ), polyethylene glycol monomethyl ether $\left(M_{\mathrm{n}}=350\right.$, Alfa Aesar), succinic anhydride (Chem-inpex, 99.9\%), phenylacetyl chloride (Alfa Aesar, 98\%), phenylacetylene (Alfa Aesar, 98+\%), 4-pentynoic acid (Chem-inpex, 98.5\%), 4-(dimethylamino) pyridine (DMAP, Aldrich, $\geq 99 \%$ ), 3-(3-dimethylaminopropyl)-1-ethyl-carbodiimide hydrochloride (EDC $\cdot \mathrm{HCl}, \mathrm{Chem}-\mathrm{impex})$, $N, N, N^{\prime}, N$ ', $N$ ' '-pentamethyldiethylenetriamine $\quad$ (PMDETA, $\quad$ Aldrich, $\quad 99 \%$ ), $N, N$-dimethylformamide (DMF, Sigma-Aldrich, $\geq 99.8 \%$ ), methanol (Sigma-Aldrich, $\geq 99.8 \%$ ), ascorbic acid (Alfa Aesar, 99+\%) and copper(II) sulfate pentahydrate $\left(\mathrm{CuSO}_{4} \cdot 5 \mathrm{H}_{2} \mathrm{O}, \mathrm{BDH}\right.$, ACS grade) were used as received. Dichloromethane (DCM, Sigma-Aldrich, $>99.5 \%$ ) was distilled over $\mathrm{CaH}_{2}$ prior to use.

Instrumental Methods. The THF size exclusion chromatography (SEC) was equipped with Polymer Standards Services (PSS) columns (guard, $10^{5}, 10^{3}$, and $10^{2} \AA$ SDV columns) at 35 ${ }^{\circ} \mathrm{C}$ with THF flow rate $=1.00 \mathrm{ml} / \mathrm{min}$, a differential refractive index $(\mathrm{RI})$ detector $($ Wyatt Technology, Optilab T-rEX) using PSS WinGPC 7.5 software. The apparent molecular weights were calculated based on linear poly(methyl methacrylate) (PMMA) standards. The detectors employed to measure the absolute molecular weights of hyperbranched polymers in THF SEC were the RI detector and a multi-angle laser light scattering (MALLS) detector (Wyatt Technology, DAWN HELEOS II) with the light wavelength at $658 \mathrm{~nm}$. Absolute molecular weights were determined using ASTRA software from Wyatt Technology with the pre-measured $\mathrm{dn} / \mathrm{dc}=0.0847$ for all hyperbranched polymers. ${ }^{3}{ }^{1} \mathrm{H}$ nuclear magnetic 
resonance (NMR) was acquired on a Bruker $500 \mathrm{MHz}$ spectrometer at $25{ }^{\circ} \mathrm{C}$ using $\mathrm{CDCl}_{3}$ or DMSO- $d_{6}$ as solvent. Differential scanning calorimetry (DSC) analyses were performed

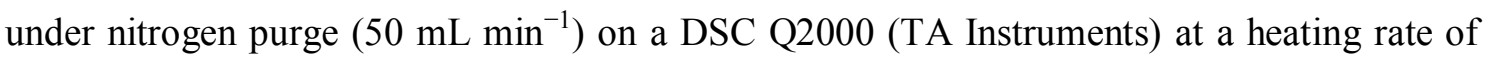
$10{ }^{\circ} \mathrm{C} \mathrm{min}-1$ and cooling rate of $20{ }^{\circ} \mathrm{C} \min ^{-1}$ and the thermograms were reported based on the second heating cycle in the temperature range of $-100-150{ }^{\circ} \mathrm{C}$. Glass transition temperature $\left(T_{\mathrm{g}}\right)$ was determined based on the automatic mode of TA Universal Analysis software. FT-IR was conducted using a Thermo Nicolet IR 200 spectrometer equipped with a deuterated triglycine sulfate (DTGS) detector, mid-IR source (4000-400 cm21) and Ge on KBr beam splitter.

\section{Synthesis of $A B_{2}-B n$}

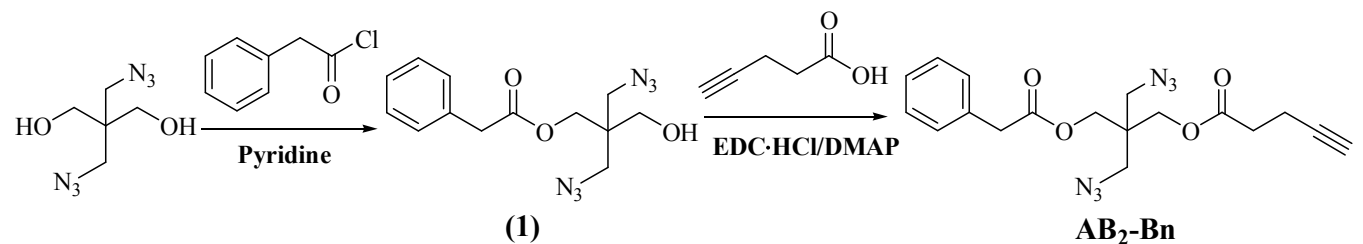

Synthesis of compound (1). 2,2-Bis(azidomethyl)propane-1,3-diol (10 g, 0.054 mol), Pyridine $(10.9 \mathrm{ml}, 0.135 \mathrm{~mol})$ and $300 \mathrm{ml}$ dried DCM were charged in a $500 \mathrm{~mL}$ dried round bottomed flask. This flask was immersed in a thermostatic ice bath at $0{ }^{\circ} \mathrm{C}$. The solution was magnetically stirred for $10 \mathrm{~min}$ before slow addition of 0.9 equiv. of phenylacetyl chloride (6.43 ml, $0.049 \mathrm{~mol})$ using a syringe pump over a period of 12 hours. The reaction was allowed to proceed for additional 12 hours at room temperature before the DCM solution was washed three times with $300 \mathrm{ml}$ brine. The organic solution was dried using anhydrous $\mathrm{MgSO}_{4}$ overnight before removing the solvent via rotary evaporation. The final product was 
purified via silica column chromatography with hexanes/diethyl ether (2/1 by volume) as the spreading solvent. The yield of compound 1 was $8.9 \mathrm{~g}(60 \%)$.

\section{Synthesis of 3-(2-phenylacetoyloxy)-2,2-bis(azidomethyl)propyl pent-4-ynoate (AB $\left.{ }_{2}-B n\right)$.}

To a round-bottom flask were added sequentially with compound $\mathbf{1}$ (8 g, $26.3 \mathrm{mmol}$ ), EDC $\cdot \mathrm{HCl}(10.3 \mathrm{~g}, 52.6 \mathrm{mmol})$, DMAP $(1.12 \mathrm{~g}, 9.2 \mathrm{mmol})$, dry DCM $(90 \mathrm{~mL})$ and 4-pentynoic acid $(2.7 \mathrm{~g}, 27.6 \mathrm{mmol}$, in $10 \mathrm{~mL}$ of DCM). The reaction mixture was allowed to be stirred at room temperature overnight before washed with water $(2 \times 100 \mathrm{~mL})$ and brine $(100 \mathrm{~mL})$ and dried over $\mathrm{MgSO}_{4}$. The solvent was evaporated, and the remaining residual was purified by silica gel chromatography (hexanes/diethyl ether, $4: 1 \mathrm{v} / \mathrm{v}$ ) to give $9.5 \mathrm{~g}$ of colorless liquid of the targeted $\mathbf{A B}_{2}-\mathbf{B n}$ monomer (90\% yield).

\section{Synthesis of $A B_{2}-E O_{x}$}
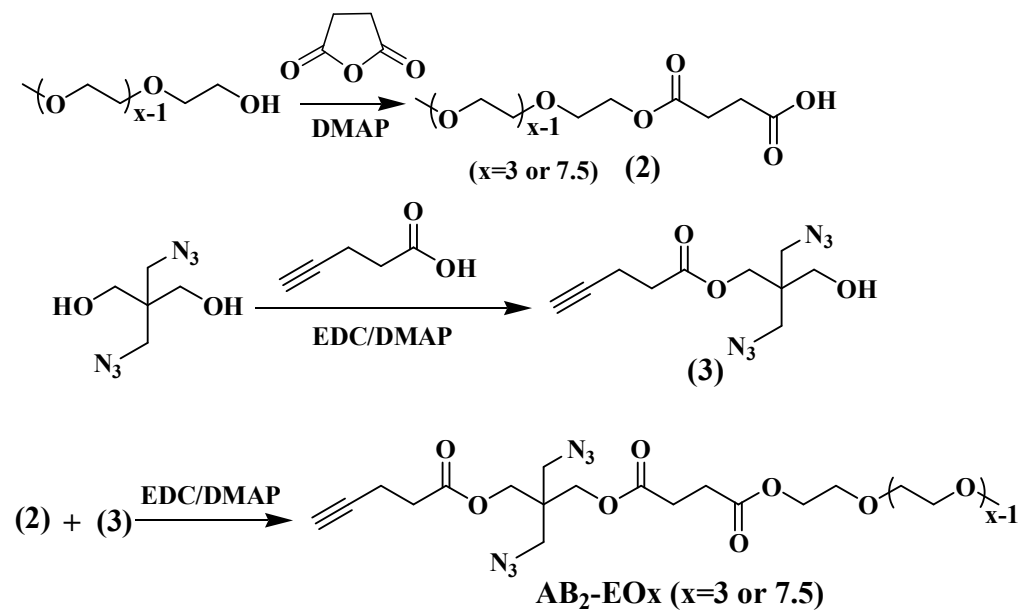

Synthesis of $\boldsymbol{m} \mathbf{E O}_{\mathrm{x}}-\mathbf{C O O H}$ (2). $m \mathrm{EO}_{\mathrm{x}}-\mathrm{COOH}$ were synthesized according to previous report. ${ }^{4}$ Typical procedures were as follows: triethylene glycol monomethyl ether $\left(m \mathrm{EO}_{3}\right)$ (20.0 g, $0.122 \mathrm{~mol})$, DMAP (2.98 g, $0.024 \mathrm{~mol})$ and succinic anhydride (14.65 g, $0.146 \mathrm{~mol})$ were dissolved in DCM $(100 \mathrm{ml})$ and left to react overnight. $50 \mathrm{ml}$ of water was then added 
to the solution followed by extraction with $\mathrm{NaHSO}_{4}(10 \%)$ three times $(3 \times 20 \mathrm{ml})$. The organic phase was then dried with $\mathrm{MgSO}_{4}$, filtered and concentrated. Yield: $90 \%$.

The procedure for preparing $m \mathrm{EO}_{7.5} \mathrm{COOH}$ was similar to that described above except for using polyethylene glycol monomethyl ether $\left(M_{\mathrm{n}}=350\right)$.

Synthesis of compound (3). 2,2-Bis(azidomethyl)propane-1,3-diol (10.0 g, $0.054 \mathrm{~mol})$, 4-pentynoic acid (3.7 g, $0.038 \mathrm{~mol}), 200 \mathrm{ml}$ dried DCM, EDC $\cdot \mathrm{HCl}(18.9 \mathrm{~g}, 0.097 \mathrm{~mol})$ and DMAP $(2.1 \mathrm{~g}, 0.017 \mathrm{~mol})$ were charged in a $500 \mathrm{~mL}$ dried round bottomed flask. This flask was immersed in a thermostatic water bath at $20{ }^{\circ} \mathrm{C}$. The reaction was allowed to proceed for 24 hours at room temperature before the DCM solution was washed three times with $3 \times 100$ $\mathrm{ml}$ brine. The organic solution was dried using anhydrous $\mathrm{MgSO}_{4}$ before removing the solvent via rotary evaporation. The final product was purified via silica column chromatography with hexanes/diethyl ether ( $3 / 1$ by volume) as the spreading solvent. The yield of compound 3 was $6.1 \mathrm{~g}(50 \%)$.

Synthesis of $\boldsymbol{A B}_{2}-\boldsymbol{E O}_{\boldsymbol{x}}$. Typical procedures for synthesis $\mathrm{AB}_{2}-\mathrm{EO}_{3}$ are described as follows: to a round-bottom flask were added sequentially with compound 3 ( $3 \mathrm{~g}, 11.3 \mathrm{mmol}), \mathrm{EDC} \cdot \mathrm{HCl}$ (4.4 g, $22.6 \mathrm{mmol})$, DMAP (0.5 g, $4.0 \mathrm{mmol})$, dry DCM $(60 \mathrm{~mL})$ and $m \mathrm{EO}_{3}-\mathrm{COOH}$ (compound 2, $3.13 \mathrm{~g}, 11.87 \mathrm{mmol}$ ). The reaction mixture was allowed to be stirred at room temperature overnight before washed with water $(2 \times 100 \mathrm{ml})$ and brine $(100 \mathrm{ml})$ and dried over $\mathrm{MgSO}_{4}$. The solvent was evaporated, and the remaining residual was purified by silica gel chromatography (hexanes/diethyl ether, $2: 1 \mathrm{v} / \mathrm{v}$ ) to give $5.3 \mathrm{~g}$ of colorless liquid of the targeted $\mathbf{A B}_{2}-\mathbf{E} \mathbf{O}_{3}$ monomer (90\% yield).

The procedure for preparing $\mathbf{A B}_{2}-\mathbf{E} \mathbf{O}_{7.5}$ was similar to that described above except for 
using $m \mathrm{EO}_{7.5}-\mathrm{COOH}$.

CuAAC polymerization of $\mathbf{A B}_{2}$ monomers in one pot. Typical procedures in the polymerization of $\mathrm{AB}_{2}-\mathrm{Bn}$ monomer using molar ratios of $\left[\mathrm{AB}_{2}-\mathrm{Bn}\right]_{0}$ : $\left[\mathrm{CuSO}_{4} \cdot 5 \mathrm{H}_{2} \mathrm{O}\right]_{0}$ : [ascorbic acid $]_{0}=100: 1: 5$ are described. $\mathrm{CuSO}_{4} \cdot 5 \mathrm{H}_{2} \mathrm{O}(5.0 \mathrm{mg}, 0.02 \mathrm{mmol})$ and $\mathrm{AB}_{2}-\mathrm{Bn}$ monomer $(0.768 \mathrm{~g}, 2.0 \mathrm{mmol})$ and $4 \mathrm{ml}$ DMF were charged in a $10 \mathrm{ml}$ flask. This flask immersed in a thermostatic oil bath at $45{ }^{\circ} \mathrm{C}$ was capped with rubber septa and bubbled with nitrogen gas for $40 \mathrm{~min}$ before the ascorbic acid $(17.6 \mathrm{mg}, 0.1 \mathrm{mmol})$ was quickly added into the flask to initiate the polymerization. Samples were collected using deoxygenated syringes at each predetermined interval and were quenched by exposure to air and the addition of a trace of PMDETA. One portion was diluted by THF and then passed through a flash alumina column for SEC measurement. Another portion was diluted by $\mathrm{CDCl}_{3}$ for the assessment of monomer conversion by ${ }^{1} \mathrm{H}$ NMR spectroscopy. The polymerization was stopped at 14 hours before the addition of 2 equiv. of PMDETA ligand to exact the $\mathrm{Cu}$ catalyst out of the polymer. The hyperbranched polymers in DCM were then passed through a flash alumina column before being precipitated in methanol three times. The final dried product was colorless solid.

The procedures for polymerization of $\mathrm{AB}_{2}-\mathrm{Bn}$ monomer in the presence of PMDETA were similar to those described above except for the addition of 1 equiv. of PMDETA to $\mathrm{CuSO}_{4} \cdot 5 \mathrm{H}_{2} \mathrm{O}$ into the system.

Synthesis of $\mathbf{H B}-\mathbf{B n}_{25} @\left(\mathbf{E O}_{3}\right)_{\mathbf{x}}$. Hyperbranched copolymers with HB-Bn 25 as core and $\mathrm{HB}-\left(\mathrm{EO}_{3}\right)_{\mathrm{x}}$ as shell were synthesized via $\mathrm{CuAAC}$ polymerization of $\mathrm{AB}_{2}$ monomers using sequential monomer addition in one pot. The procedure for polymerization of $\mathrm{AB}_{2}$ monomer was as follows. The first batch of polymerization was conducted at molar ratios of $\left[\mathrm{AB}_{2}-\mathrm{Bn}\right]_{0}$ : 
$\left[\mathrm{CuSO}_{4} \cdot 5 \mathrm{H}_{2} \mathrm{O}\right]_{0}:$ ascorbic acid $]_{0}=25: 1: 5$ in DMF with $\left[\mathrm{AB}_{2}-\mathrm{Bn}\right]_{0}=0.5 \mathrm{~mol} / \mathrm{L}$. After reaching a complete monomer conversion $(>98 \%)$, a $2^{\text {nd }}$ batch of deoxygenated $\mathrm{AB}_{2}-\mathrm{EO}_{3}$ (100 equiv. to initial $\mathrm{Cu})$ in $\mathrm{DMF}(0.5 \mathrm{~mol} / \mathrm{L}$ of monomer) was added into the reaction system. Samples were collected using deoxygenated syringes at each predetermined interval and were quenched by exposure to air and the addition of a trace of PMDETA. The hyperbranched copolymers in DCM were then passed through a flash alumina column before being precipitated in diethyl ether three times.

The procedure for preparing hyperbranched copolymers with $\mathrm{HB}-\left(\mathrm{EO}_{3}\right)_{25}$ as core and $\mathrm{HB}-(\mathrm{Bn})_{\mathrm{y}}$ as shell was similar to that described above except for using $\mathrm{AB}_{2}-\mathrm{EO}_{3}$ in the $1^{\text {st }}$ batch and $\mathrm{AB}_{2}-\mathrm{Bn}$ in the $2^{\text {nd }}$ batch.

The procedure for preparing hyperbranched copolymers with multi-segmented structure was similar to that described above except for repeating monomer addition.

End capping of hyperbranched polymer. Typical procedure for synthesizing HB-Bn $25-c a p-\mathrm{EO}_{3}$ was as follows: HB-Bn-3 $\left(0.2 \mathrm{~g}, 0.52 \mathrm{mmol}\right.$ of $\left.-\mathrm{N}_{3}\right)$, ay- $\mathrm{EO}_{3}(0.34 \mathrm{~g}, 1.04$ mmol), $\mathrm{CuSO}_{4} \cdot 5 \mathrm{H}_{2} \mathrm{O}(5 \mathrm{mg}, 0.02 \mathrm{mmol})$ and $2 \mathrm{~mL}$ DMF were charged in a $10 \mathrm{~mL}$ flask. The mixture was degassed by three freeze-pump-thaw cycles, and then the ascorbic acid (17.6 mg, $0.1 \mathrm{mmol}$ ) was added into flask. The flask was sealed under vacuum and the click reaction was carried out in an oil bath at $45{ }^{\circ} \mathrm{C}$. The reaction was stopped at 4 hours before the addition of 2 equiv. of PMDETA ligand to exact the $\mathrm{Cu}$ catalyst out of the polymer. The hyperbranched polymers in DCM were then passed through a flash alumina column before being precipitated in diethyl ether three times. The final dried product was colorless with a yield around $80 \%$. 
The procedure for preparing hyperbranched polymers $\mathrm{HB}-\left(\mathrm{EO}_{3}\right)_{25}-\mathrm{cap}-\mathrm{Ph}$ was similar to that described above except that $\mathrm{HB}-\left(\mathrm{EO}_{3}\right)_{25}$ and phenylacetylene were used.

(A)

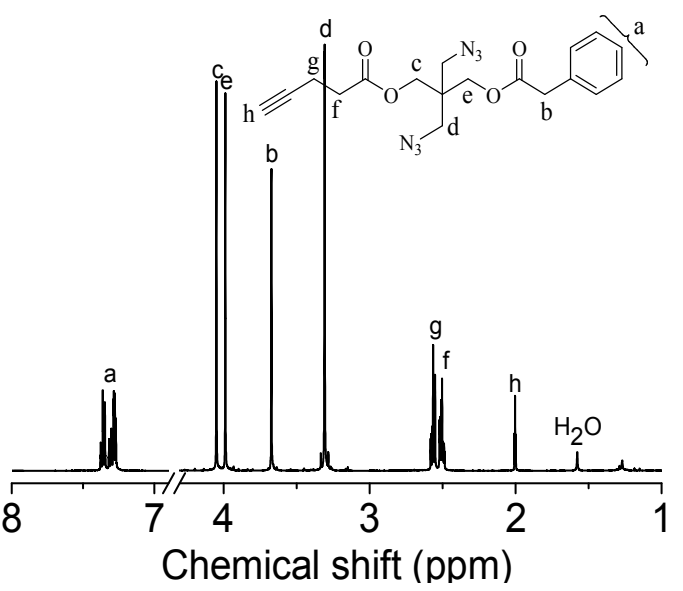

(B)

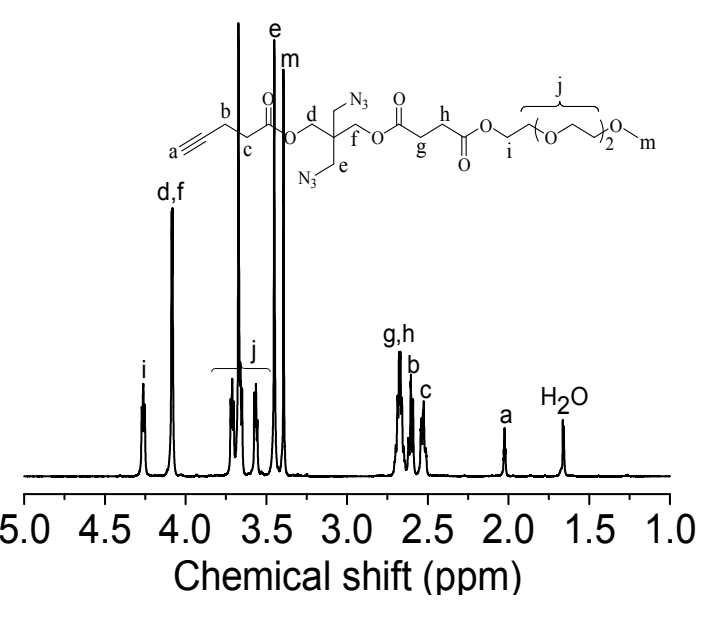

(C)

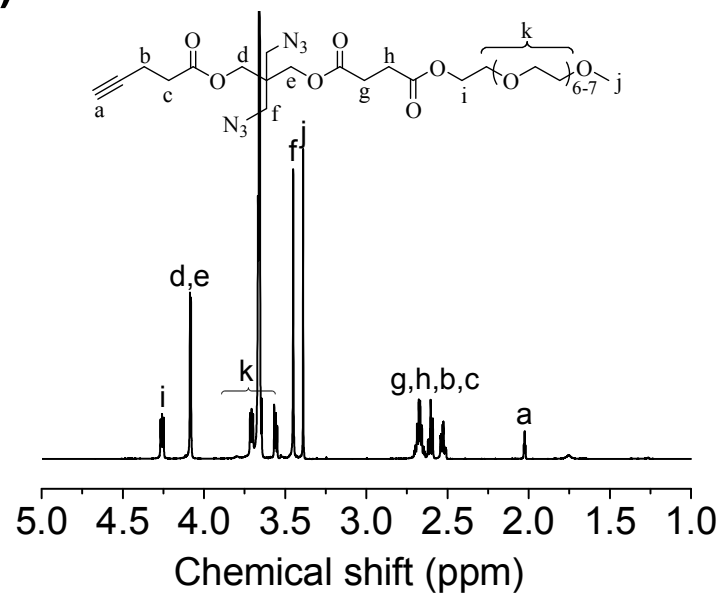

Figure S1. ${ }^{1} \mathrm{H}$ NMR spectra of $(\mathrm{A}) \mathrm{AB}_{2}-\mathrm{Bn}$, (B) $\mathrm{AB}_{2}-\mathrm{EO}_{3}$ and (C) $\mathrm{AB}_{2}-\mathrm{EO}_{7.5}$ monomers in $\mathrm{CDCl}_{3}$ at $25{ }^{\circ} \mathrm{C}$. 


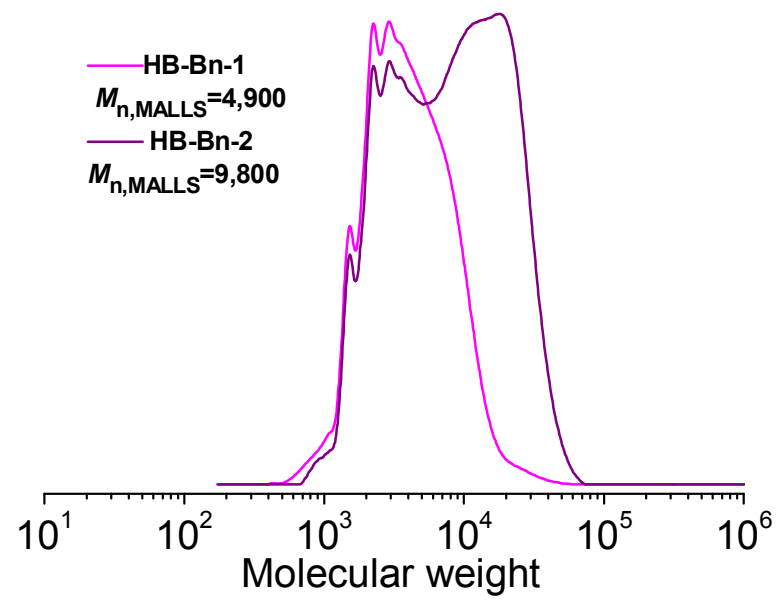

Figure S2. SEC traces of HB-Bn-1 and HB-Bn-2, which were synthesized from a step-growth $\mathrm{CuAAC}$ polymerization of $\mathrm{AB}_{2}-\mathrm{Bn}$ monomer in the presence of 1 equiv. PMDETA ligand.

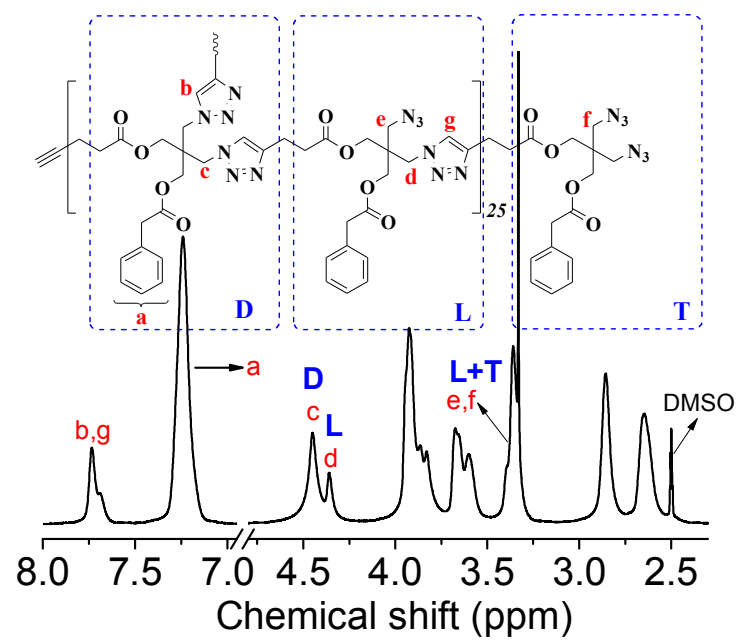

Figure S3. ${ }^{1} \mathrm{H}$ NMR spectrum of hyperbranched polymer $\mathrm{HB}-\mathrm{Bn}-3\left(\mathrm{HB}-\mathrm{Bn}_{25}\right)$ in $\mathrm{CDCl}_{3}$.

Using the equation $\mathrm{DB}=2 \mathrm{D} /(2 \mathrm{D}+\mathrm{L}),{ }^{5-6}$ the $\mathrm{DB}$ value of hyperbranched polymers (HB-Bn) with different molecular weight was calculated to be $0.79-0.82$. The DB values of the series of $\mathrm{HB}-\mathrm{EO}_{\mathrm{x}}$ polymers were calculated using similar method. 
(A)

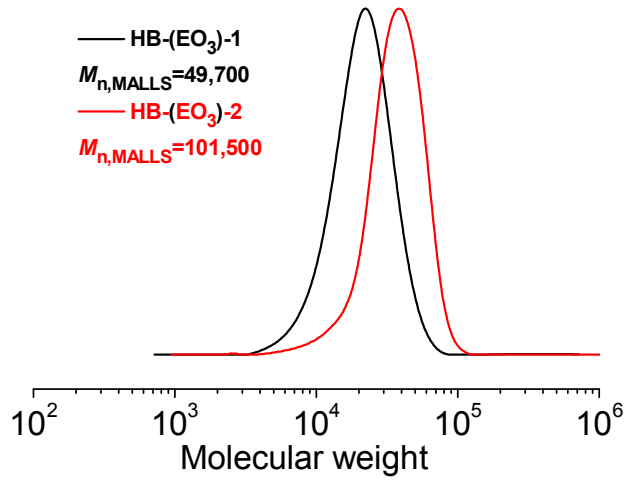

(B)

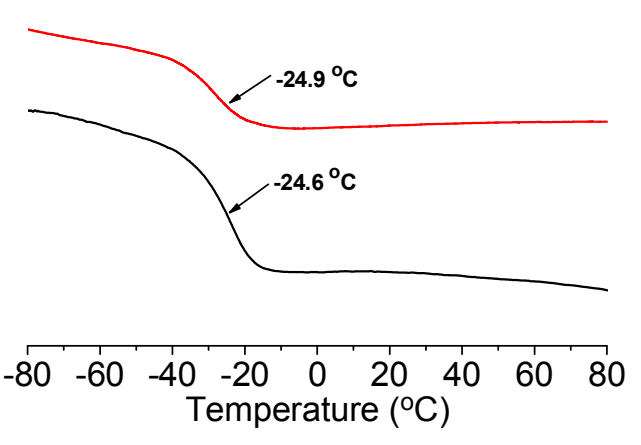

Figure S4. (A) SEC traces and (B) DSC curves of HB-(EO $\left.{ }_{3}\right)-1$ and HB-(EO $\left.{ }_{3}\right)-2$.

(A)

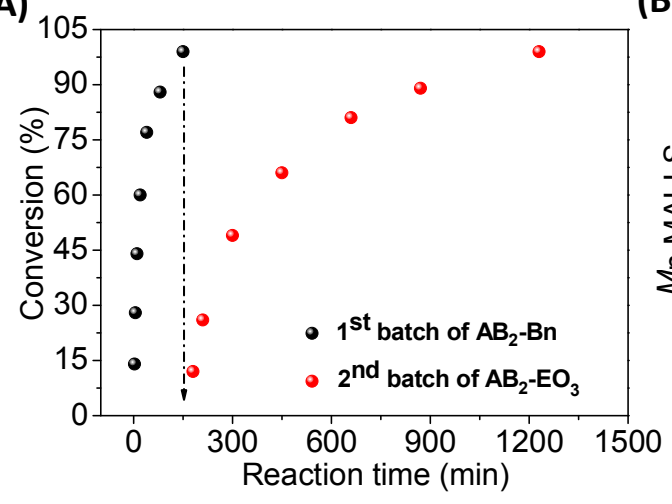

(B)

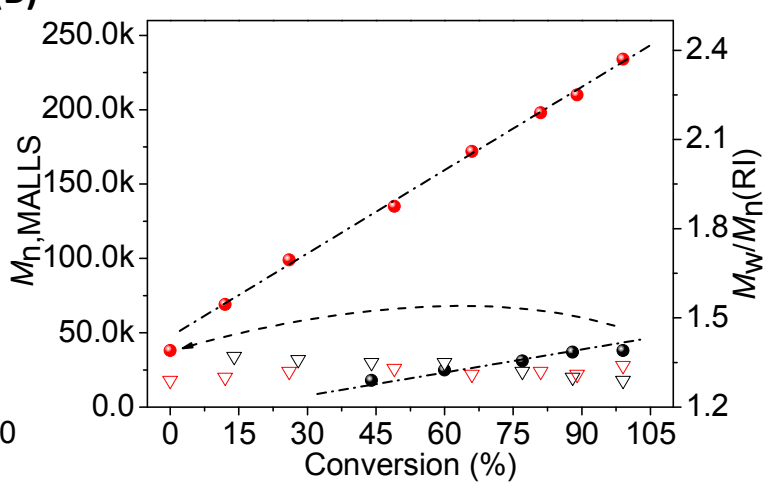

Figure S5. A) Dependence of conversion on reaction time and B) evolution of the number-average molecular weight $\left(M_{\mathrm{n}, \mathrm{MALLS}}\right)$ and polydispersity index $\left(M_{\mathrm{w}} / M_{\mathrm{n}}\right.$, RI detector) as a function of conversion in the one-pot CuAAC polymerization: the $1^{\text {st }}$ batch of $\mathrm{AB}_{2}-\mathrm{Bn}$ monomer at feed ratios of $\left[\mathrm{AB}_{2}-\mathrm{Bn}\right]_{0} /\left[\mathrm{CuSO}_{4} \cdot 5 \mathrm{H}_{2} \mathrm{O}\right]_{0} /[\text { ascorbic acid }]_{0}=25: 1: 5$ in DMF at 45 ${ }^{\circ} \mathrm{C},\left[\mathrm{AB}_{2}\right]_{0}=0.5 \mathrm{~mol} / \mathrm{L}$, and the $2^{\text {nd }}$ batch of $\mathrm{AB}_{2}-\mathrm{EO}_{3}$ monomer (100 equiv. to the initial amount of $\mathrm{Cu}$ ). 
(A)

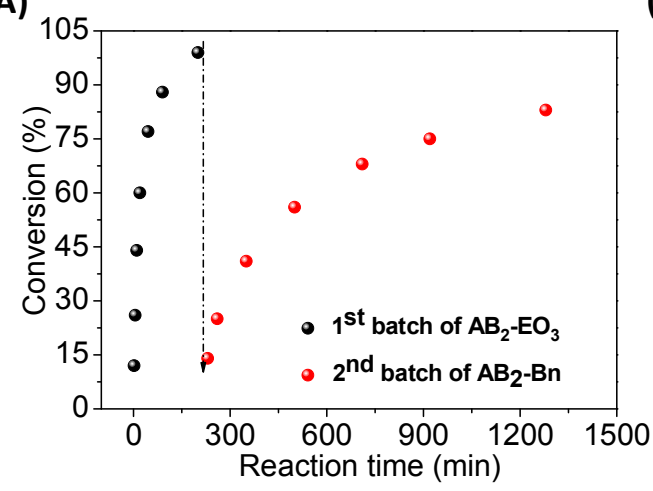

(B)

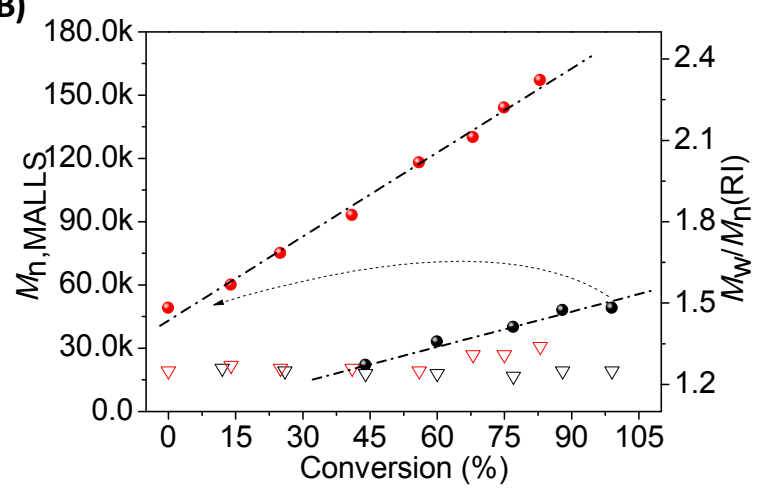

Figure S6. A) Dependence of conversion on reaction time and B) evolution of the number-average molecular weight $\left(M_{\mathrm{n}, \mathrm{MALLS}}\right)$ and polydispersity index $\left(M_{\mathrm{w}} / M_{\mathrm{n}}\right.$, RI detector $)$ as a function of conversion in the one-pot $\mathrm{CuAAC}$ polymerization: the $1^{\text {st }}$ batch of $\mathrm{AB}_{2}-\mathrm{EO}_{3}$ monomers at feed ratios of $\left[\mathrm{AB}_{2}-\mathrm{EO}_{3}\right]_{0} /\left[\mathrm{CuSO}_{4} \cdot 5 \mathrm{H}_{2} \mathrm{O}\right]_{0} /[\text { ascorbic acid }]_{0}=25: 1: 5$ in $\mathrm{DMF}$ at $45{ }^{\circ} \mathrm{C},\left[\mathrm{AB}_{2}\right]_{0}=0.5 \mathrm{~mol} / \mathrm{L}$, and the $2^{\text {nd }}$ batch of $\mathrm{AB}_{2}-\mathrm{Bn}$ monomer (100 equiv. to the initial amount of $\mathrm{Cu})$.

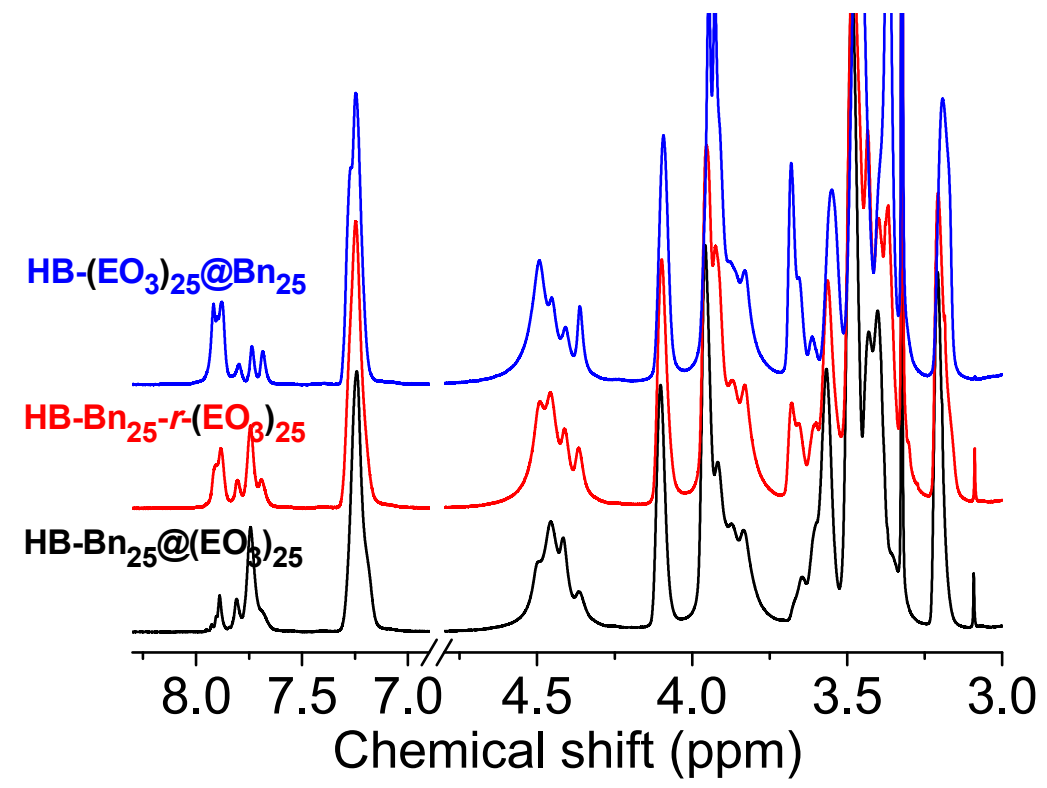

Figure S7. Overlaid ${ }^{1} \mathrm{H}$ NMR spectra of segmented hyperbranched copolymers $\mathrm{HB}-\mathrm{Bn}_{25} @\left(\mathrm{EO}_{3}\right)_{25}, \mathrm{HB}-\mathrm{Bn}_{25}-r-\left(\mathrm{EO}_{3}\right)_{25}$ and HB-(EO $)_{25} @ \mathrm{Bn}_{25}$. 
(A)

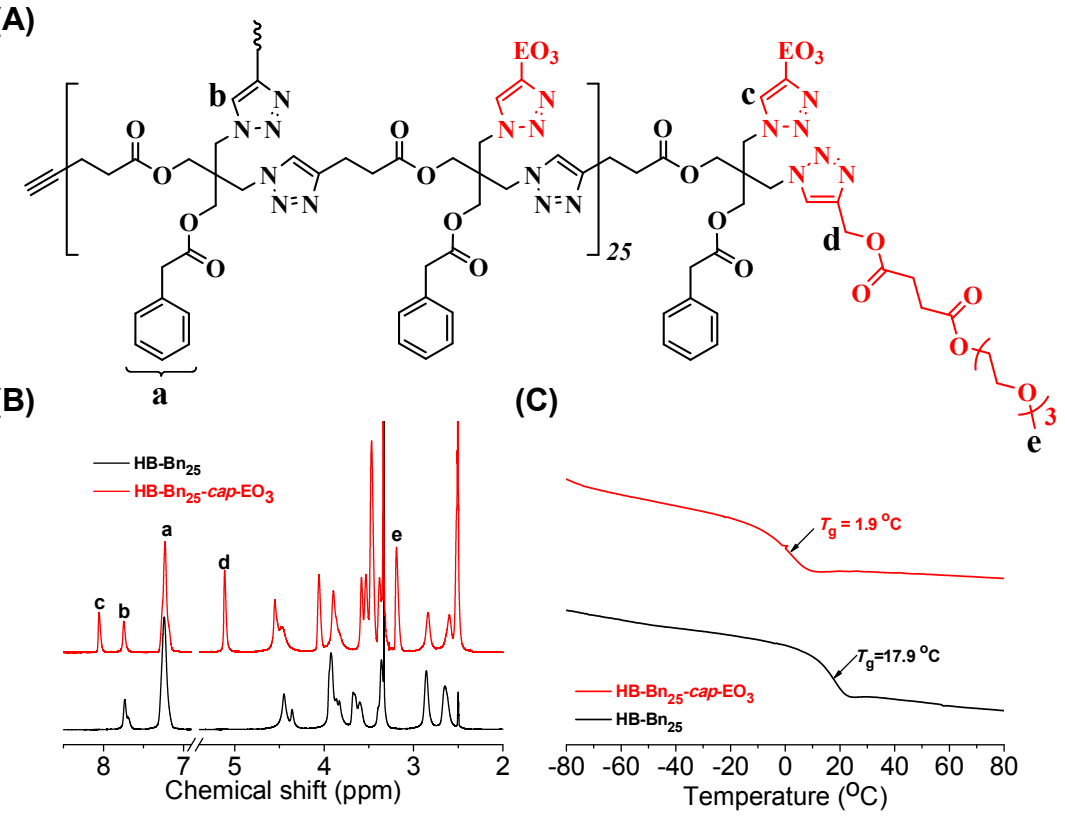

Figure S8. (A) Representative structure of $\mathrm{HB}-\mathrm{Bn}_{25}-\mathrm{cap}-\mathrm{EO}_{3}$, (B) ${ }^{1} \mathrm{H}$ NMR spectra and (C) DSC curves of $\mathrm{HB}-\mathrm{Bn}_{25}$ and $\mathrm{HB}-\mathrm{Bn}_{25}-$ cap $-\mathrm{EO}_{3}$

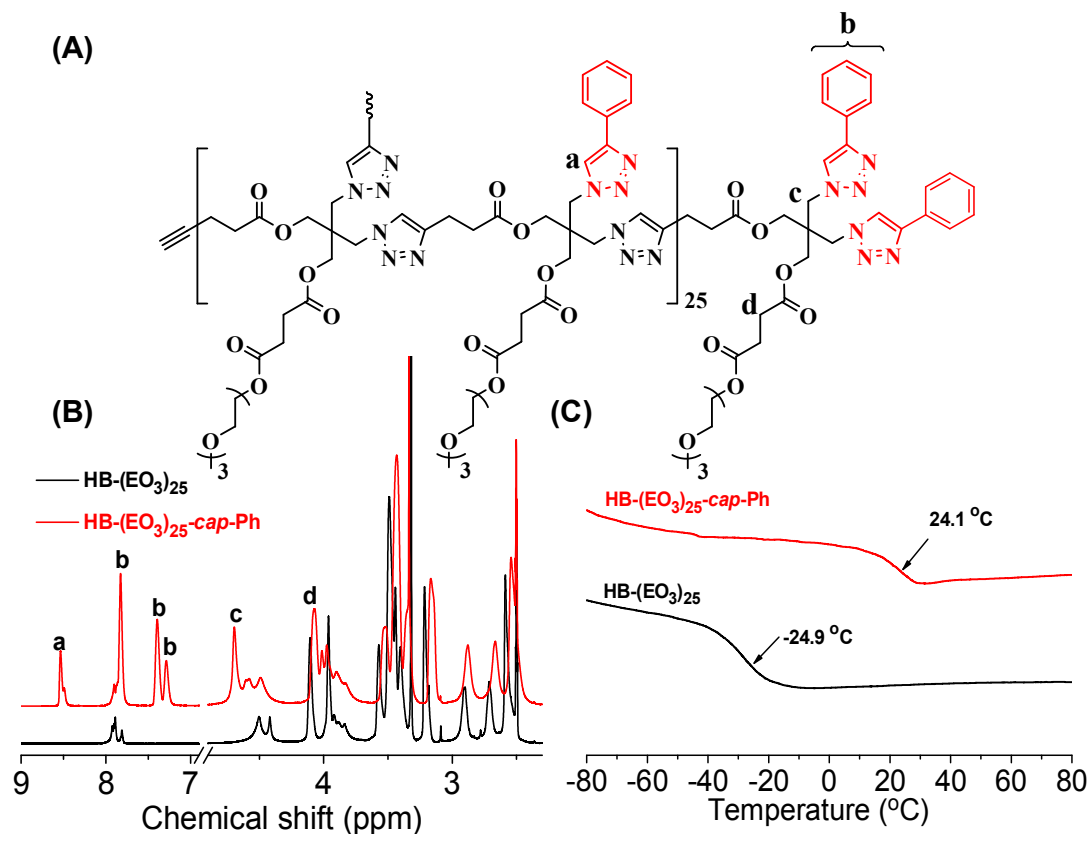

Figure S9. (A) Representative structure of HB-(EO $)_{25}-c a p-\mathrm{Ph},(\mathrm{B}){ }^{1} \mathrm{H}$ NMR spectra and (C) DSC curves of $\mathrm{HB}-\left(\mathrm{EO}_{3}\right)_{25}$ and $\mathrm{HB}-\left(\mathrm{EO}_{3}\right)_{25}-\mathrm{cap}-\mathrm{Ph}$ 


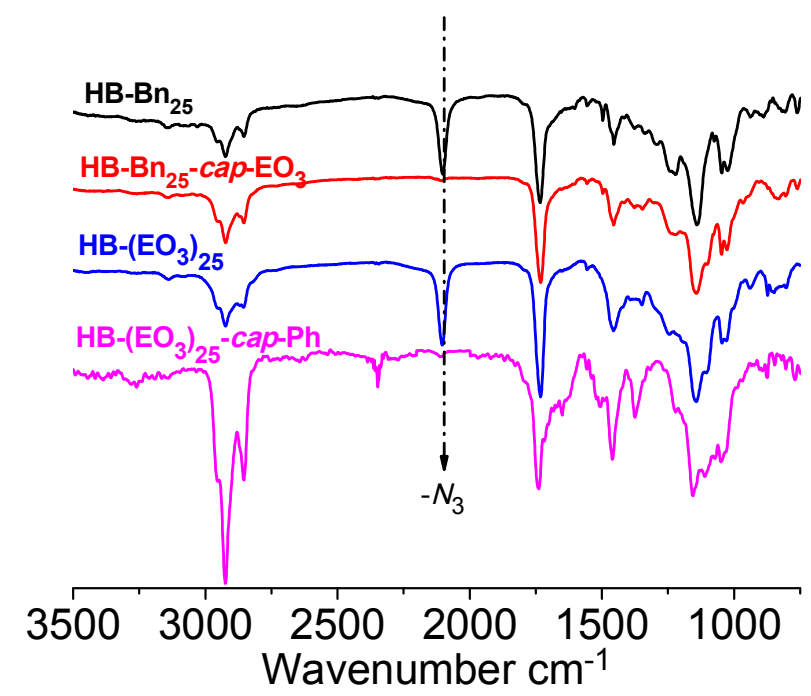

Figure S10. FT-IR spectra of $\mathrm{HB}-\mathrm{Bn}_{25}, \mathrm{HB}-\mathrm{Bn}_{25}-\mathrm{cap}-\mathrm{EO}_{3}, \mathrm{HB}-\left(\mathrm{EO}_{3}\right)_{25}$ and $\mathrm{HB}-\left(\mathrm{EO}_{3}\right)_{25}-\mathrm{cap}-\mathrm{Ph}$

(A)

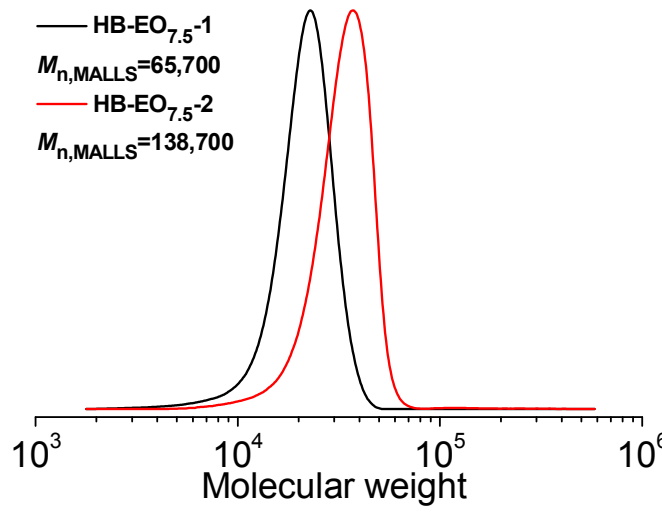

(B)
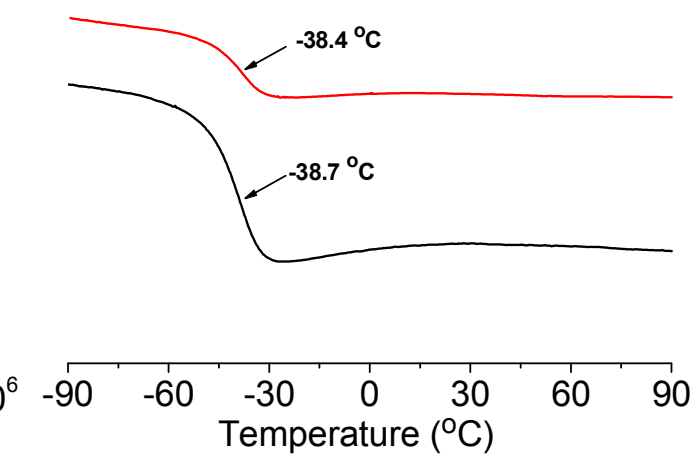

Figure S11. (A) SEC traces and (B) DSC curves of HB-(EO $\left.{ }_{7.5}\right)-1$ and HB-(EO $\left.\mathrm{EO}_{7.5}\right)-2$. 


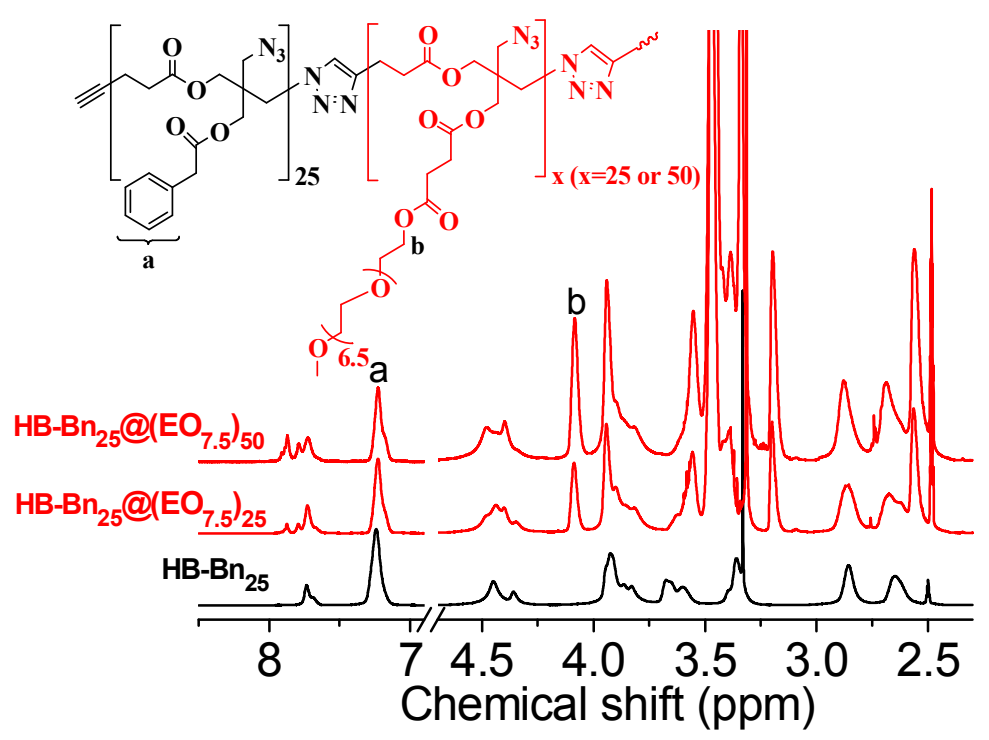

Figure S12. ${ }^{1} \mathrm{H}$ NMR spectra of HB-Bn $25, \mathrm{HB}-\mathrm{Bn}_{25} @\left(\mathrm{EO}_{7.5}\right)_{25}$ and HB-Bn ${ }_{25} @\left(\mathrm{EO}_{7.5}\right)_{50}$.

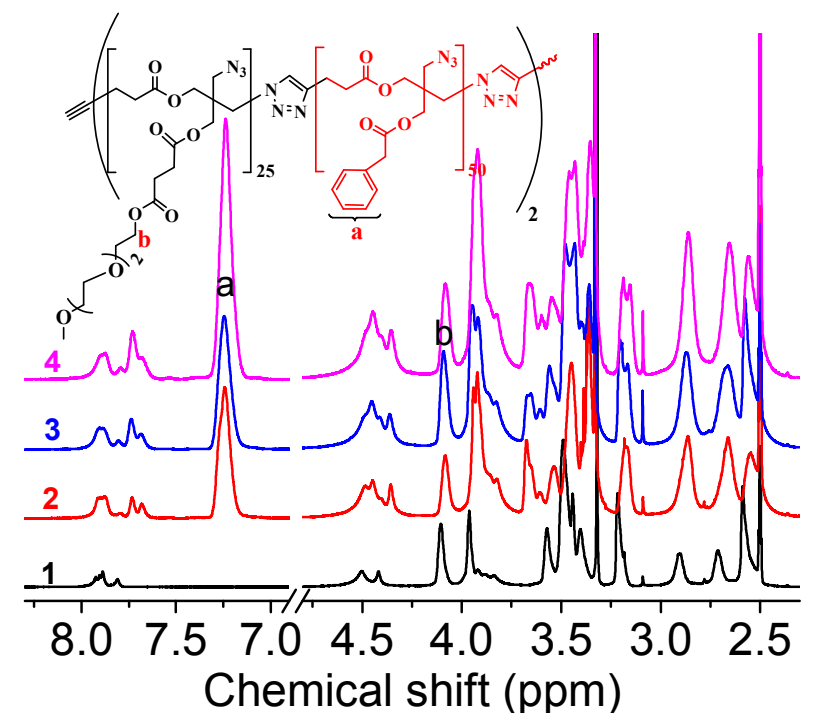

Figure S13. ${ }^{1} \mathrm{H}$ NMR spectra of (1) HB- $\left(\mathrm{EO}_{3}\right)_{25}, \quad(2) \mathrm{HB}-\left(\mathrm{EO}_{3}\right)_{25} @ \mathrm{Bn}_{50}$,

HB-(EO3) $)_{25} @ \mathrm{Bn}_{50} @\left(\mathrm{EO}_{3}\right)_{25}$ and (4) HB-(EO $)_{25} @ \mathrm{Bn}_{50} @\left(\mathrm{EO}_{3}\right)_{25} @ \mathrm{Bn}_{50}$.

\section{References}

1. Xu, J.; Prifti, F.; Song, J., A Versatile Monomer for Preparing Well-Defined Functional Polycarbonates and Poly(ester-carbonates). Macromolecules 2011, 44, 
2660-2667.

2. Shi, Y.; Graff, R. W.; Cao, X.; Wang, X.; Gao, H., Chain-Growth Click Polymerization of $\mathrm{AB}_{2}$ Monomers for the Formation of Hyperbranched Polymers with Low Polydispersities in a One-Pot Process. Angew. Chem., Int. Ed. 2015, 54, 7631-7635.

3. Cao, X.; Shi, Y.; Wang, X.; Graff, R. W.; Gao, H., Design a Highly Reactive Trifunctional Core Molecule To Obtain Hyperbranched Polymers with over a Million Molecular Weight in One-Pot Click Polymerization. Macromolecules 2016, 49, 760-766.

4. Antoni, P.; Hed, Y.; Nordberg, A.; Nyström, D.; von Holst, H.; Hult, A.; Malkoch, M., Bifunctional Dendrimers: From Robust Synthesis and Accelerated One-Pot Postfunctionalization Strategy to Potential Applications. Angew. Chem., Int. Ed. 2009, 48, 2126-2130.

5. Hölter, D.; Burgath, A.; Frey, H., Degree of branching in hyperbranched polymers. Acta Polym. 1997, 48, 30-35.

6. Frey, H., Degree of branching in hyperbranched polymers. 2. Enhancement of the db: Scope and limitations. Acta Polym. 1997, 48, 298-309. 